\title{
Patient Safety Risks of Basic Urological Procedures Performed by Junior and Senior Residents
}

Citation for published version (APA):

de Vries, A. H., Boute, M. C., Kuppen, M. C. P., van Merrienboer, J. J. G., Koldewijn, E. L., Pelger, R. C. M., Schout, B. M. A., \& Wagner, C. (2015). Patient Safety Risks of Basic Urological Procedures Performed by Junior and Senior Residents. Journal of Surgical Education, 72(5), 918-926. https://doi.org/10.1016/j.jsurg.2015.04.014

Document status and date:

Published: 01/01/2015

DOI:

10.1016/j.jsurg.2015.04.014

Document Version:

Publisher's PDF, also known as Version of record

Document license:

Taverne

Please check the document version of this publication:

- A submitted manuscript is the version of the article upon submission and before peer-review. There can be important differences between the submitted version and the official published version of record.

People interested in the research are advised to contact the author for the final version of the publication, or visit the DOI to the publisher's website.

- The final author version and the galley proof are versions of the publication after peer review.

- The final published version features the final layout of the paper including the volume, issue and page numbers.

Link to publication

\footnotetext{
General rights rights.

- You may freely distribute the URL identifying the publication in the public portal. please follow below link for the End User Agreement:

www.umlib.nl/taverne-license

Take down policy

If you believe that this document breaches copyright please contact us at:

repository@maastrichtuniversity.nl

providing details and we will investigate your claim.
}

Copyright and moral rights for the publications made accessible in the public portal are retained by the authors and/or other copyright owners and it is a condition of accessing publications that users recognise and abide by the legal requirements associated with these

- Users may download and print one copy of any publication from the public portal for the purpose of private study or research.

- You may not further distribute the material or use it for any profit-making activity or commercial gain

If the publication is distributed under the terms of Article $25 \mathrm{fa}$ of the Dutch Copyright Act, indicated by the "Taverne" license above, 


\title{
Patient Safety Risks of Basic Urological Procedures Performed by Junior and Senior Residents
}

\author{
Anna H. de Vries, MD, * Maaike C. Boute, MD, ${ }^{\dagger}$ Malou C.P. Kuppen, MD, *
} Jeroen J.G. van Merriënboer, PhD, ${ }^{\ddagger}$ Evert L. Koldewijn, MD, PhD, * $\neq$ Rob C.M. Pelger, MD, PhD,, Barbara M.A. Schout, MD, PhD, I, 'I and Cordula Wagner, PhD ${ }^{\mathrm{Il}, \#}$

*Department of Urology, Catharina Hospital, Eindhoven, The Netherlands; 'Department of Surgery, Westfriesgasthuis, Hoorn, The Netherlands; *Faculty of Health, Medicine and Life Sciences, Maastricht University Medical Center, Maastricht, The Netherlands; ${ }^{\circledR}$ Department of Urology, University Medical Center Leiden, Leiden, The Netherlands; "Department of Urology, St. Antonius Hospital, Nieuwegein, The Netherlands; II Netherlands Institute for Health Services Research (NIVEL), Utrecht, The Netherlands; and \#Department of Public and Occupational Health, EMGO Institute for Health and Care Research, Amsterdam, The Netherlands

OBJECTIVE: To investigate the current performance of urological residents regarding basic urological procedures in relation to patient safety issues and the identification of specific training needs.

DESIGN: Observational data of 146 urethrocystoscopies (UCSs), 27 transrectal ultrasounds of the prostate (TRUSs), 38 transrectal ultrasound-guided prostatic biopsies (TRUSPs), and 30 transurethral resections of bladder tumor (TURBTs) were collected. Performance was evaluated using scoring lists including details on completeness of procedural steps, level of independence, time, and the incidence of unintended events. The causal factors contributing to the unintended events were identified by 2 expert urologists and classified according to the recognized PRISMA method.

SETTING: This study was performed in 5 teaching hospitals in the Netherlands.

PARTICIPANTS: We included 11 junior residents and 5 senior residents in urology in the final study cohort.

RESULTS: Senior residents showed a lower degree of completeness in material usage than junior residents did during UCS $(\mathrm{p}<0.01)$ and in preparation, material usage, and procedure during TRUSP (all $\mathrm{p}<0.05$ ). In UCS and TURBT, senior residents received significantly less feedback than junior residents did (both $\mathrm{p}<0.01$ ). Incidence of unintended events for junior vs senior residents was $11 \%$

Correspondence: Inquiries to Anna H. de Vries, MD, Department of Urology, Catharina Hospital Eindhoven, Michelangelolaan 2, 5623 EJ Eindhoven, The Netherlands; fax: (402) 39-6021.; e-mail: a.h.de.vries@hotmail.com and $4 \%$ in UCS, $0 \%$ and $7 \%$ in transrectal ultrasound of the prostate, $36 \%$ and $62 \%$ in TRUSP, and $41 \%$ and $23 \%$ in TURBT, respectively. Overall, unintended events were mainly caused by human factors, in particular, verification and skills-based issues.

CONCLUSION: Present performance of basic urological procedures involves a high percentage of unintended events, especially in TRUSP and TURBT, which are mainly caused by human factors and are a potential threat for patient safety. Junior residents are less independent but more thorough in the performance of UCS and TRUSP than senior residents are. Targeted skills training including assessment should be implemented before privileges for independent practice are granted to reduce the incidence of unintended events and optimize patient safety. ( $\mathrm{J}$ Surg Ed 72:918-926. ๑ 2015 Association of Program Directors in Surgery. Published by Elsevier Inc. All rights reserved.)

KEY WORDS: task performance, resident, urology, adverse event, patient safety, practical skills training

COMPETENCIES: Patient Care, Practice-Based Learning and Improvement, Systems-Based Practice

\section{INTRODUCTION}

Traditionally, urological residents learned their practical skills according to the master-apprentice type of training. ${ }^{1}$ However, times are changing, and the former way of training is facing multiple challenges. Owing to evolving medical technology in combination with decreasing 
numbers of patient-related training hours, barriers are raised in achieving appropriate levels of proficiency during residency training. ${ }^{2-4}$ The introduction of technically complex minimally invasive surgery has resulted in an increased frequency of complications, particularly during the early learning curve. ${ }^{5}$ Furthermore, nowadays, performing a first procedure directly on the patient is becoming unacceptable. The standards for clinician proficiency are higher, and more importance is placed on patient safety in today's legal environment. ${ }^{6,7}$ Consequently, there is a need for alternative forms of training to reduce errors and shorten the patient-related learning curve. Thus, simulation training is a growing field in addition to the master-apprentice approach. $^{8-11}$

"The learning curve of a certain urological procedure is the period during which a surgeon in training finds the procedure more difficult, takes longer to complete, there is higher rate of complications and lower efficacy due to inexperience." 12 Owing to interindividual differences in technical ability and previous experience, it is impossible to specify a standard number of procedures for residents to reach proficiency. Instead, it has been suggested to define proficiency levels that have to be met before a resident or urologist is deemed to be competent to perform a certain procedure. $^{12}$

In literature, relatively many studies have been described that investigated learning curves, risks, and training needs of complex urological procedures, such as (robot assisted) laparoscopic radical prostatectomy. ${ }^{12-14}$ However, very little is known about the learning curves and training needs of more basic urological procedures, such as prostate biopsies or transurethral resection of bladder tumors (TURBT). Although these procedures are less complex, they do have a large effect on patient safety, comfort, and outcomes, oncological or otherwise. ${ }^{15-17}$ Every urologist should fully master these practical skills.

In this study, we investigated the current performance of urological residents regarding basic urological procedures, in relation to patient safety issues and the identification of specific training needs. The aim was to answer the following research question: "How well do junior and senior residents perform on the patient regarding 4 basic urological procedures, considering completeness of procedural steps, level of independence, intervention time, and the incidence of unintended events?"

\section{MATERIAL AND METHODS}

We observed the procedures, urethrocystoscopy (UCS), transrectal ultrasound of the prostate (TRUS), transrectal ultrasound-guided prostatic biopsies (TRUSP), and TURBT, performed by urological residents in 5 teaching hospitals spread across the Netherlands between July 2012 and February 2013. The urological residency program consists of a 4-year traineeship in which practical skills are trained in a patient-related setting. Before this traineeship, all residents participate in a 2-day practical course. During this mandatory course, the basic urological skills (including UCS, TRUS[P], and TURBT) are trained in a non-patientrelated setting on simulation models. Moreover, the 4 years of urology training include 8 other obligatory practical skills courses (e.g., sonography, endourology, and electrosurgery).

Residents in their first and second year of urological training and residents waiting for acceptance as full residents were categorized as "junior residents." Participants in their third and fourth year of urological training were categorized as "senior residents." Written informed consent was obtained from all participants, and the data were processed anonymously. Ethical approval was obtained from the institutions ethics committee.

\section{Practice Setting and Supervision}

The diagnostic procedures UCS and TRUS(P) are performed at the outpatient clinic, and the TURBT in the operating room. Faculty supervision is a routine part of training and practice in the residency program. However, for the diagnostic procedures (UCS, TRUS, and TRUSP), continuous faculty supervision is only present in the first months of residency training. When a supervisor considers the resident to be competent in the performance of the diagnostic procedure, the resident performs the procedure without continuous supervision, although supervision is available upon request. Moreover, supervision after the procedure, by means of discussing images or pictures that are saved during the procedure, is a routine part of training. For procedures performed in the operating room (such as TURBT), a faculty supervisor is always present. The only exception is for residents in the final phase of residency training. In preparation for their upcoming independent practice, it is possible to perform a procedure without continuous supervision. Again, this occurs only if the responsible faculty member considers the resident to be competent in the performance of the procedure.

\section{Observations}

To evaluate the performance of residents, a scoring list was developed for the 4 procedures. This scoring list contained information on completeness of procedural steps, level of independence, time, and the incidence of unintended events.

\section{Completeness of Procedural Steps}

For each procedure, all separate steps were identified by consulting 2 expert urologists and 2 residents. A detailed list of procedural steps was composed and divided into 5 categories: preparation, communication, material usage, procedure, and registration. Completeness of procedural 
steps was calculated as the number of performed steps per category divided by the total number of steps per category, multiplied by 100 .

\section{Level of Independence}

Level of independence was reflected by the incidence of a physical intervention by the supervisor and the amount of received feedback during the procedure. Incidence of a physical intervention was calculated as the number of procedures in which a supervisor intervened divided by the total number of procedures multiplied by 100 . Feedback was categorized into feedback that was requested by the resident and unrequested feedback that was given by the supervisor.

\section{Time}

Time was categorized into total time and procedural time. Total time was defined as "patient entering the OR to patient leaving the OR." Procedural time was defined as "gloves on to gloves off."

\section{Unintended Events}

Unintended events were identified by the observer during the procedure and described in detail. Subsequently, 2 experts in urology (E.K. and R.P.) assessed whether the event could be classified as a near-miss or an adverse event, using commonly used definitions (Table 1). ${ }^{18,19}$ After this, the underlying cause of the events was reviewed by the same 2 experts and classified into 5 main causal factor categories: technical, organizational, human, patient related, and other. Having opted for 1 of these categories, if possible, a more detailed subcategory of the causal factors was selected. The causal factor categories were derived from a recognized taxonomy of root causes: the Eindhoven Classification Model of PRISMA-Medical, a root cause analysis tool. ${ }^{20,21}$ The definitions of the causal factor categories and subcategories are presented in Table 2.

\section{Pilot study}

Before the start of the actual study, 2 researchers (M.K. and M.B.) conducted 2 pilot studies that included 41 and 36 procedures, respectively, in 3 hospitals (data were not included in the final study). This pilot was primarily conducted to optimize and internally validate the scoring list. Overall, $7 \%$ of the procedures in the first pilot study were observed by 2 independent observers. The interobserver agreement was calculated using Cohen $\mathrm{\kappa}$ coefficient, in which a $\kappa$ value of 0 corresponds to an agreement equivalent to chance and a $\kappa$ value of 1.0 corresponds to perfect agreement. The interobserver agreement was 0.8 , which is indicated to be a substantial agreement. ${ }^{22}$ Besides the validation of the scoring list, the pilot studies also enabled the residents and supervising urologists to get accustomed to the observations. After the pilot studies, procedures were observed by 1 researcher (M.K., M.B., or A.d.V.). To minimize the effect on the environment under study, the observer did not participate in the procedure.

\section{Data analysis}

Values for variables (completeness of procedural steps, feedback, and time) were not normally distributed and are presented as medians with their range (minimum-maximum). For the evaluation of unintended events and their causes, descriptive statistics and frequency tables were used. Mann-Whitney $U$ tests were performed to compare continuous variables between junior and senior residents. An $\alpha$ level of 0.05 was considered statistically significant. Analyses were performed using the Statistical Package for Social Sciences (SPSS) version 20.0 (SPSS, Chicago, IL).

\section{RESULTS}

Between July 2012 and February 2013, observational data of 146 UCS, 27 TRUS, 38 TRUSP, and 30 TURBT procedures were collected. Data collection was performed in 5 teaching hospitals, and all available residents in these hospitals were included in the study. Details regarding the distribution of junior and senior residents per procedure and the presence of a supervisor are given in Table 3.

Table 4 presents the results of performance during UCS, TRUS, TRUSP, and TURBT and the incidence of unintended events during these 4 procedures. In total, 6 adverse events $(3 \%)$ and 35 near misses $(15 \%)$ were identified. The distribution of the causal factors of these unintended events is reflected in the Figure. The main causal factor of total cases was found in the subcategory "verification" within the category human rule-based behavior (15/41, 37\%). The main causal factor for senior residents was in this same subcategory $(9 / 41,22 \%)$. For junior residents, the main causal factor for unintended events was found in the

TABLE 1. Definition of Adverse Event and Near Miss

Unintended Event

Definition

Adverse event

An unintended injury that results in temporary or permanent disability, death, or prolonged hospital stay, and that is caused by health care management rather than by the patient's underlying disease process Near miss A mistake that does not reach the patient or, if it reaches the patient, does not result in injury or harm

Definitions are derived from Jagsi et al. ${ }^{18}$ and Zegers et al. ${ }^{19}$ 
TABLE 2. Definitions of the Causal Factor Categories and Subcategories of Unintended Events

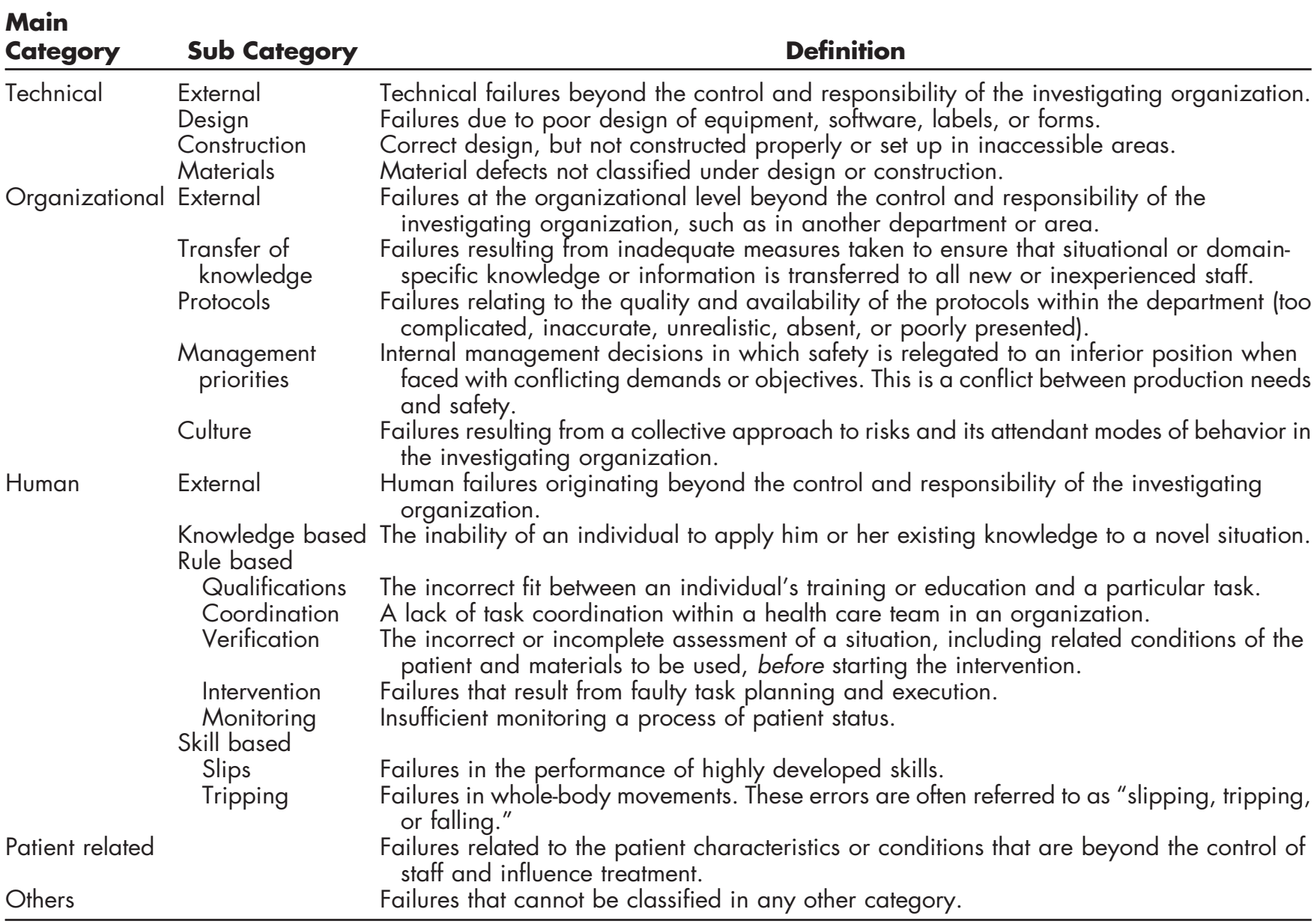

Descriptions are derived from Van Vuuren et al. ${ }^{20}$ and Van der Schaaf and Habraken. ${ }^{21}$

subcategory "slips" in the category human skill-based behavior $(8 / 41,20 \%)$. The definition of a slip is "a failure in the performance of a highly developed skill," and it can thus be a human skill-based underlying cause for both near misses (unintended event with no harm for the patient) and adverse events (unintended event with harm for the patient). Details of the unintended events and their causes are described later.

\section{Performance of UCS}

Median completeness of procedural steps in the preparation and communication category was $50 \%$ and $67 \%$ for junior and senior residents, respectively. These relatively low percentages appeared to be caused by the fact that residents frequently did not ask the patient about complaints of urinary tract infection and hematuria and frequently did not perform a physical examination. Considering communication, especially the provision of instructions before and after UCS, was relatively low. Senior residents did less well on "material usage" ( $p<0.01$ ), mainly because they failed to perform "white balance" more often than junior residents did. In total, 12 unintended events occurred, all of which were classified as near misses and none as adverse events. There were 4 near misses that were due to "slips" (failure in performance of highly developed skills). In 2 cases, the supervisor identified abnormalities in the bladder that were not identified by the residents, both of whom were junior residents. The 2 other slips involved vaginal introduction of the cystoscope and inability to introduce the cystoscope. There were 4 near misses that were due to "construction" issues, e.g., faulty light settings and disintegration of the cystoscope during the procedure; 2 near misses were due to organizational issues, which concerned requests for a supervisor who was not present or delayed; and 2 near misses were due to verification and communication errors.

\section{Performance of TRUS}

Median completeness of procedural steps in the material usage category was $100 \%$ for junior and 50\% for senior residents ( $\mathrm{p}<$ $0.01)$. This difference was mainly because more senior residents did not adjust the settings of the ultrasound machine to assess the prostate and measure the volume. There was 1 unintended event that occurred. This was a near miss and concerned a 
TABLE 3. Distribution of Residents per Procedure and the Presence of a Supervisor

\begin{tabular}{|c|c|c|c|c|c|c|c|c|}
\hline \multirow{2}{*}{$\begin{array}{l}\text { Procedure } \\
\text { Level of training }\end{array}$} & \multicolumn{2}{|c|}{ UCS $(n=146)$} & \multicolumn{2}{|c|}{ TRUS $(n=27)$} & \multicolumn{2}{|c|}{ TRUSP $(n=38)$} & \multicolumn{2}{|c|}{ TURBT $(n=30)$} \\
\hline & Junior & Senior & Junior & Senior & Junior & Senior & Junior & Senior \\
\hline $\begin{array}{l}\text { Participants ( } n) \\
\text { Procedures executed per resident } \\
\text { (median [min-max]) }\end{array}$ & $\begin{array}{c}11 \\
7.5[1-19]\end{array}$ & $\begin{array}{c}5 \\
9[4-21]\end{array}$ & $\begin{array}{l}7 \\
1[1-5]\end{array}$ & $\begin{array}{c}3 \\
6[3-6]\end{array}$ & $\begin{array}{c}8 \\
2[1-7]\end{array}$ & $\begin{array}{c}3 \\
5[5-6]\end{array}$ & $\begin{array}{c}7 \\
2[1-6]\end{array}$ & $\begin{array}{c}5 \\
3[1-4]\end{array}$ \\
\hline $\begin{array}{l}\text { Procedures executed total } \\
\text { Supervisor present }\end{array}$ & $\begin{array}{c}95 / 146(65 \%) \\
41 / 95(43 \%)\end{array}$ & $\begin{array}{c}51 / 146(35 \%) \\
14 / 51(28 \%)\end{array}$ & $\begin{array}{l}12 / 27(44 \%) \\
5 / 12(42 \%)\end{array}$ & $\begin{array}{c}15 / 27(56 \%) \\
2 / 15(13 \%)\end{array}$ & $\begin{array}{c}22 / 38(58 \%) \\
8 / 22(36 \%)\end{array}$ & $\begin{array}{c}16 / 38(42 \%) \\
1 / 16(6 \%)\end{array}$ & $\begin{array}{l}17 / 30(57 \%) \\
17 / 17(100 \%)\end{array}$ & $\begin{array}{l}13 / 30(43 \%) \\
11 / 13(85 \%)\end{array}$ \\
\hline
\end{tabular}

* For UCS, TRUS, and TRUSP, the supervisor was present during the complete procedure for junior residents in the beginning of their learning curve and otherwise upon request. For TURBT, the supervisor was present throughout the complete procedure.

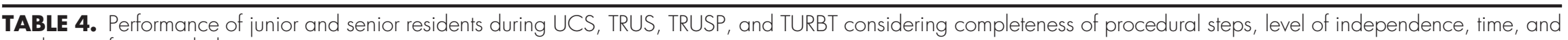
incidence of unintended events

\begin{tabular}{|c|c|c|c|c|c|c|c|c|c|c|c|c|}
\hline \multirow{2}{*}{$\begin{array}{l}\text { Procedure } \\
\text { Level of training }\end{array}$} & \multicolumn{3}{|c|}{ UCS } & \multicolumn{3}{|c|}{ TRUS } & \multicolumn{3}{|c|}{ TRUSP } & \multicolumn{3}{|c|}{ TURBT } \\
\hline & Junior & Senior & $\mathbf{p}$ & Junior & Senior & $\mathbf{p}$ & Junior & Senior & $\mathbf{p}$ & Junior & Senior & $\mathbf{p}$ \\
\hline \multicolumn{13}{|c|}{ Completeness of procedural steps (\%) } \\
\hline Preparation & $50[0-100]$ & $50[0-100]$ & 0.32 & 100 [50-100] & $100[100-100]$ & 0.11 & $100[75-100]$ & 75 [33-100] & $<0.01$ & $71[25-100]$ & $67[50-86]$ & 0.78 \\
\hline Communication & $67[0-100]$ & $67[0-100]$ & 0.36 & $67[0-100]$ & $67[33-100]$ & 0.11 & $100[25-100]$ & $100[50-100]$ & 0.25 & $100[0-100]$ & $100[0-100]$ & 0.39 \\
\hline Material usage & $100[33-100]$ & 50 [50-100] & $<0.01$ & $100[67-100]$ & $50[50-100]$ & $<0.01$ & $100[67-100]$ & $75[0-100]$ & $<0.01$ & $67[33-100]$ & $75[50-75]$ & 0.36 \\
\hline Procedure & $86[50-100]$ & $82[57-100]$ & 0.24 & $100[56-100]$ & 89 [78-100] & 0.08 & $93[86-100]$ & 86 [69-100] & 0.02 & $84[50-100]$ & 80 [70-95] & 0.43 \\
\hline Registration & $78[17-100]$ & $75[25-100]$ & 0.34 & $88[50-100]$ & $88[50-100]$ & 0.19 & $61[12-88]$ & $53[31-88]$ & 0.1 & $60[0-100]$ & $67[50-100]$ & 0.19 \\
\hline Total & $75[47-100]$ & $70[45-93]$ & 0.02 & $83[61-92]$ & $83[72-96]$ & 0.96 & 82 [53-95] & 74 [54-90] & $<0.01$ & 70 [57-97] & $74[64-82]$ & 0.23 \\
\hline \multicolumn{13}{|l|}{ Level of independence } \\
\hline Intervention supervisor & $9 / 95(10 \%)$ & $0 / 51(0 \%)$ & 0.11 & $0 / 12(0 \%)$ & $0 / 15(0 \%)$ & 1.00 & $1 / 22(5 \%)$ & $0 / 16(0 \%)$ & 0.39 & $13 / 17$ (77\%) & $3 / 13(23 \%)$ & 0.04 \\
\hline Requested feedback $(n)^{*}$ & $1[0-4]$ & 1 [ 10-1] & 0.33 & $1[1-3]$ & $1.5[1-2]$ & 0.83 & 2 [0-10] & $1[1-1]$ & 0.54 & $3[0-24]$ & $3[0-9]$ & 0.33 \\
\hline Unrequested feedback $(n)^{*}$ & 1 [0-15] & $0[0-1]$ & 0.02 & $0[0-16]$ & $1[0-2]$ & 0.83 & $10.5[1-31]$ & $1[1-1]$ & 0.17 & $22[1-96]$ & $4[0-18]$ & $<0.01$ \\
\hline \multicolumn{13}{|l|}{ Intervention time (min) } \\
\hline Total time & $19[5-40]$ & $15[4-47]$ & $<0.01$ & $13[8-27]$ & $12[6-42]$ & 0.54 & $22[14-38]$ & 20 [13-25] & 0.12 & $45[19-74]$ & $41[20-61]$ & 0.42 \\
\hline Procedural time & $6[1-15]$ & $5[1-26]$ & 0.03 & $5[2-9]$ & $5[2-6]$ & 0.77 & $12[7-25]$ & $10[5-17]$ & 0.11 & $36[7-61]$ & 31 [18-45] & 0.63 \\
\hline Unintended events & 10/95 (11\%) & $2 / 51(4 \%)$ & $n / a$ & $0 / 12(0 \%)$ & $1 / 15(7 \%)$ & $n / a$ & $8 / 22(36 \%)$ & $10 / 16(62 \%)$ & $n / a$ & $7 / 17(41 \%)$ & $3 / 13(23 \%)$ & $n / a$ \\
\hline Adverse event & $0 / 95(0 \%)$ & $0 / 51(0 \%)$ & & $0 / 12(0 \%)$ & $0 / 15(0 \%)$ & & $3 / 22(14 \%)$ & $1 / 16(6 \%)$ & & $2 / 17(12 \%)$ & $0 / 13(0 \%)$ & \\
\hline Near miss & 10/95 (11\%) & $2 / 51(4 \%)$ & & $0 / 12(0 \%)$ & $1 / 15(7 \%)$ & & $5 / 22(22 \%)$ & $9 / 16(56 \%)$ & & $5 / 17(29 \%)$ & $3 / 13(23 \%)$ & \\
\hline
\end{tabular}




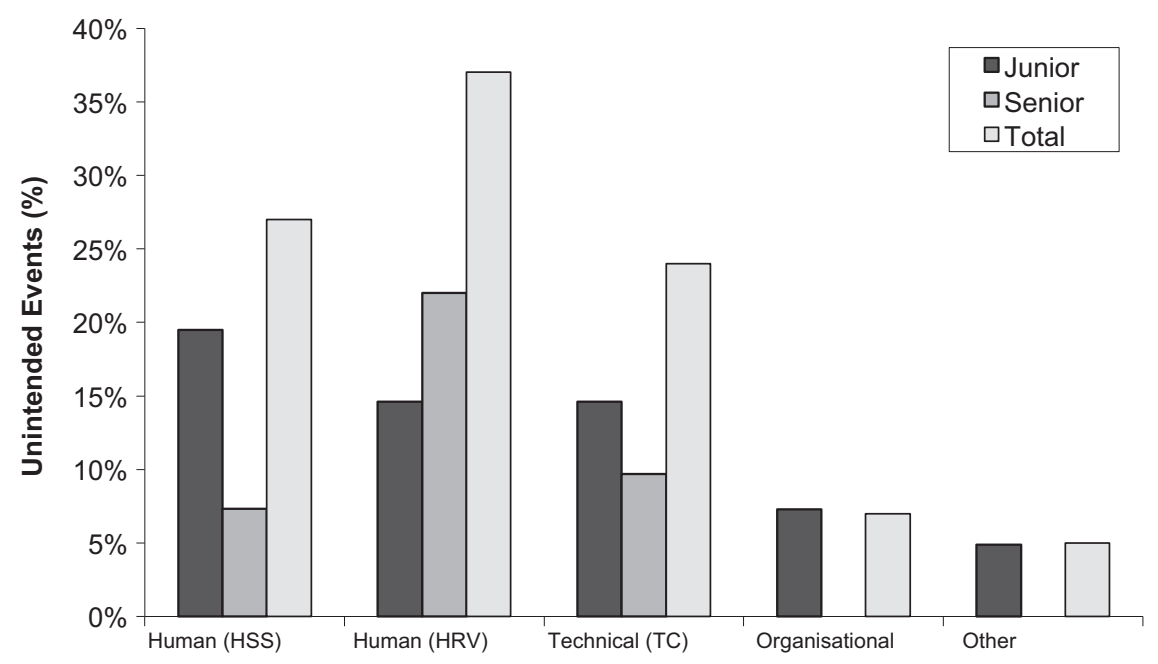

FIGURE. Distribution of main causes of unintended events for junior and senior residents. Reviewers could select 1 causal factor per unintended event. HSS, human skill-based behavior, subcategory "slips"; HRV, human rule-based behavior, subcategory "verification"; TC, technical, subcategory "construction."

"verification" issue, namely the need to reset the ultrasound machine while the probe had already been introduced, because the settings were still based on the former patient.

\section{Performance of TRUSP}

In TRUSP, senior residents were significantly less complete in the categories preparation, material usage, and procedure than junior residents were (all $\mathrm{p}<0.05$ ). In particular, more senior residents failed to check whether the patient took his or her prescribed antibiotics $(\mathrm{p}<0.05)$. Also, more senior residents did not adjust the settings of the ultrasound machine to assess the prostate and measure the volume. Consequently, fewer senior residents measured the volume.

Median completeness of procedural steps in the registration category was $61 \%$ and $53 \%$ (junior and senior, respectively). These relatively low percentages were because of a lack of procedural details in the patient file and incomplete specification on the pathology form.

In total, 18 unintended events occurred: 4 adverse events and 14 near misses. All adverse events were due to "slips," namely the necessity to take extra biopsies because tissue fragments were too small. One near miss was also due to a "slip" issue, namely dislocation of the probe, requiring it to be taken out and to be introduced again. In 18\% of TRUSP (7/38; 2/7 junior, 5/7 senior), residents failed to check whether the patient used/stopped anticoagulants. In $8 \%$ of TRUSP (3/38; all senior residents), they failed to check whether patients took the prescribed antibiotics (verification issue). Moreover, 1 near miss owing to "verification" involved an ultrasound machine that was found to be defunct although the probe had already been introduced. Of the last 2 near misses, 1 was due to a technical problem with the screen of the ultrasound (construction) and the other was due to a communication error.

\section{Performance of TURBT}

Median completeness of procedural steps in the preparation category was $71 \%$ and $67 \%$ (junior and senior, respectively). In the material usage category, this was $67 \%$ for juniors and $75 \%$ for seniors. These relatively low percentages were caused by omission of bimanual examination $(65 \%$ and $59 \%)$, omission of white balance $(69 \%$ and $62 \%)$, and failure to check diathermia settings $(75 \%$ and 69\%) (junior and senior residents, correspondingly).

In total, 10 unintended events occurred: 2 adverse events and 8 near misses. Both the adverse events involved (suspicion of) bladder perforation ("slips") by junior residents. In 1 of these cases, the scope had not been assembled correctly, causing the biopsy forceps to protrude too far, which increased the risk of bladder perforation. In the next 3 TURBT, this incorrect construction was not noticed, leading to 3 near misses due to a persistent higher risk of bladder perforation. Another near miss involved coagulation while the resident was not looking at the screen ("slip"). Finally, 4 near misses were caused by "verification," "construction," and "organizational" issues, e.g., disintegration of the resectoscope and delay owing to waiting for new materials because of nonsterility.

\section{DISCUSSION}

In this study, we investigated the current performance of junior and senior urological residents during UCS, TRUS, TRUSP, and TURBT, in relation to patient safety issues and the identification of specific training needs. We showed 
that, especially in UCS and TURBT, there was a remarkable lack in preparation and registration. Junior residents appeared to be less independent but more complete in the performance of UCS and TRUSP than senior residents were. A high incidence of unintended events was identified, particularly in TRUSP and TURBT (47\% and 33\%, respectively). These events were mainly caused by human factors and posed a potential threat for patient safety. The results of this study indicate that the current way of teaching practical skills, based on to the master-apprentice model, is not sufficient.

UCS, TRUS, and TRUSP are procedures that are generally performed at the outpatient clinic by junior and senior residents without continuous supervision. The results of this study show that especially the risk of errors during TRUSP is underestimated, which was reflected by the high incidence of unintended events, constituting a potential threat for patient safety. Moreover, despite the fact that TURBT was nearly always performed in the presence of a supervisor, a high incidence of unintended events was revealed during this procedure as well.

These results are disturbing, and they underline the need to develop and introduce preventive strategies. One strategy could be repeated non-patient-related practical skills training and assessment for junior and senior residents. In the theory of Ericsson, deliberate practice is described as 1 of the most important ingredients for obtaining automaticity in skills. ${ }^{23}$ The process of learning a practical skill can be divided into 3 phases. ${ }^{24}$ In the first phase, the focus is on accuracy and quality. Speed and time are emphasized in a second phase, and at last, time sharing is introduced to achieve full automaticity of the skill. If basic skills were repeatedly trained to automaticity in a non-patient-related setting, residents could focus on the performance of the actual procedure and its procedural steps in the clinical setting. This would shift a part of the learning curve from the patient to a non-patient-related (skills laboratory) setting. The results of this study will be used in the development of targeted practical skills training for junior and senior residents. Specific attention is directed to the causal factors of the unintended events to prevent repetition in the future. Moreover, predefined proficiency levels should be assessed before privileges for independent practice are granted, to confirm that the degree of proficiency is sufficient. This relates to the concept of "entrustable professional activities" (EPA), introduced by Ten Cate. ${ }^{25}$ An EPA is an activity that a resident can be trusted to perform competently. It is a way to translate competencies into clinical practice. ${ }^{25} \mathrm{EPA}$ assessment enables supervisors to know when a resident can be trusted to perform specific procedures with minimal or no supervision in different stages of the training. Our results are expected to provide a more solid basis for EPAs than rather arbitrary numbers of performed procedures in clinical practice, for which a scientific basis is typically lacking. ${ }^{26,27}$
Verification issues appeared to be the most important cause of the near misses during TRUSP. This was mainly because of failure of asking the patient about the use of anticoagulants and antibiotics before the start of the procedure, which introduced the potential risk of complications such as prolonged rectal bleeding and urosepsis. The reason why residents failed to check this with the patient could be owing to simply forgetting it or perhaps to the assumption that it would already have been checked by a nurse. This issue can be overcome by introducing a safety checklist. Checklists have been used as an intervention to prevent adverse events, and the implementation of the WHO surgical safety checklist was shown to reduce postoperative complications and mortality. ${ }^{28,29}$ The development and implementation of a checklist for TRUSP could prevent the near misses due to verification issues and optimize patient safety.

In this study, the amount of requested feedback during the procedures was low, especially for the diagnostic procedures. There are several explanations for this low level of requested feedback. First, a patient who undergoes a diagnostic procedure is not asleep and thus aware of the communication between the resident and the supervisor. Consequently, a resident might not discuss all his or her thoughts and considerations during the procedure, in the presence of the patient, but merely before or after the procedure. Moreover, there is a possibility to save images of potential pathological findings and discuss these images with a supervisor after the procedure. Unfortunately, information regarding requested feedback after the procedure is not available, as the observations stopped after the patient left the examination room. Finally, gathering information by asking questions is certainly not the only way by which a procedure is learned. The main focus while conducting the procedure seemed to be on learning by doing, which is an effort-demanding learning process. This could also have the consequence of limited requested feedback by the resident.

Variability in supervision did not seem to have an effect on the rate of intervention. The rate of intervention for the performance of TURBT procedures, including only the procedures in which a supervisor was present, was $77 \%$ in the junior group vs $27 \%$ in the senior group. This significant difference shows that senior residents experienced less intervention because they are actually more proficient and not because the attending physician is not there to intervene. For the procedures UCS and TRUS(P), this is not so clearly reflected in the results, as the level of supervision and rate of intervention were much lower. However, senior residents are only scheduled for the performance of independent procedures if the responsible faculty member considers them to perform the procedure safely and competent. This means that superior proficiency is expected in this group.

Interestingly, senior residents appeared to be significantly faster in UCS and to receive less feedback in UCS and TURBT, but they were also less complete in the performance 
of procedural steps during UCS and TRUSP than junior residents were. This finding is in concordance with the process of skills acquisition described earlier. ${ }^{30}$ Novices follow the teachers' instructions and apply rules and procedures step by step. However, with increasing experience, clinicians can generate the same outcomes faster and more efficiently. ${ }^{30}$ Moreover, the process used to solve problems changes after solving the same type of problem repeatedly, often resulting in steps being skipped. ${ }^{31}$ Patient safety could be endangered if a resident unconsciously makes a wrong judgement regarding skipping certain steps, thus raising the phenomenon of "unconscious incompetence." 32,33 In TRUSP, the omission of asking patients about their use of antibiotics and anticoagulants resulted in a high incidence of near misses and induced a potential risk for patient safety. In conclusion, experience is crucial in the ability to make a safe judgement regarding skipping procedural steps in a specific task. Adequate supervision, skills training, and assessment are necessary to optimize patient safety.

\section{Limitations}

The qualitative observation method used in this study has its limitations, because it is dependent on the observers' ability to interpret events accurately. Variation between observers is possible. We therefore internally validated the scoring list by a thorough pilot study and reached the substantial interobserver agreement of 0.8 before observers performed the observations alone. ${ }^{22}$

Owing to logistical issues, data collection was limited to 5 of 25 Dutch teaching hospitals. However, these hospitals were spread across the country, representing different educational regions. Moreover, all urological residents working in those hospitals were included in the study. Unfortunately, the distribution of junior to senior residents in the included hospitals was not 1:1, leading to inclusion of more junior than senior residents. The observations were conducted based on the availability of residents, resulting in a variable number of observations per resident. Statistical correction for clustering was not possible owing to the limited number of observations. Box plots were made for material usage and total time in UCS (data not shown), which showed that some clustering occurred, and some residents showed consistently higher or lower results. However, unintended events were not consistently caused by individual residents. As this study included residents from all training years in 5 teaching hospitals spread across the country, we believe our data to be representative for the current performance and risks of the particular procedures.

The limited number of unintended events that were identified within the different procedures made it impossible to perform a reliable statistical analysis regarding the relationship between level of training and rate of unintended events. However, as the unintended events were not consistently caused by junior or senior residents, it seems that a clear relationship between level of training and rate of unintended events was not present. Finally, the primary focus in this study was on the identification of unintended events that occurred during the procedure and the evaluation of its causes. The consequences of the unintended events (patient outcomes after the procedure and after discharge) were not measured. This would be an interesting line of research for future studies.

\section{CONCLUSION}

The present performance of basic urological procedures involves a high percentage of unintended events, especially in TRUSP and TURBT, which are mainly caused by human factors and result in a potential threat for patient safety. In UCS and TURBT, there is a remarkable lack in preparation and registration. Junior residents are slower and less independent but more thorough in the performance of UCS and TRUSP than senior residents are. Targeted skills training including assessment should be implemented before privileges for independent practice are granted to reduce the incidence of unintended events and optimize patient safety.

\section{ACKNOWLEDGMENTS}

The authors gratefully acknowledge Saskia Houterman for statistical advice, Lisette van Hulst for editorial assistance, and all residents for their participation in this study.

\section{REFERENCES}

1. Halsted W. The training of the surgeon. Bull Johns Hopkins Hosp. 1904;15:267-276.

2. Kelly BD, Curtin PD, Corcoran M. The effects of the European Working Time Directive on surgical training: the basic surgical trainee's perspective. Ir J Med Sci. 2011;180(2):435-437.

3. Parsons BA, Blencowe NS, Hollowood AD, Grant JR. Surgical training: the impact of changes in curriculum and experience. J Surg Educ. 2011;68(1):44-51.

4. Scott DJ. Patient safety, competency, and the future of surgical simulation. Simulation Healthc. 2006;1(3): 164-170.

5. Gallagher AG. Metric-based simulation training to proficiency in medical education: what it is and how to do it. Ulster Med J. 2012;81(3):107-113.

6. Shaw K, Cassel CK, Black C, Levinson W. Shared medical regulation in a time of increasing calls for accountability and transparency: comparison of recertification in the United States, Canada, and the United Kingdom. J Am Med Assoc. 2009;302(18):2008-2014. 
7. Hout FA, Nienhuis ED, Robben PB, Frederiks BJ, Legemaate J. Supervision by the Dutch Healthcare Inspectorate. Eur J Health Law. 2010;17(4):347-360.

8. Rodriguez-Paz JM, Kennedy M, Salas E, et al. Beyond "see one, do one, teach one": toward a different training paradigm. Postgrad Med J. 2009;85(1003): 244-249.

9. Reznick RK, MacRae H. Teaching surgical skillschanges in the wind. N Engl J Med. 2006;355(25): 2664-2669.

10. Rogers DA. Ethical and educational considerations in minimally invasive surgery training for practicing surgeons. Semin Laparosc Surg. 2002;9(4):206-211.

1 1. Ahmed K, Jawad M, Dasgupta P, Darzi A, Athanasiou T, Khan MS. Assessment and maintenance of competence in urology. Nat Rev Urol. 2010;7(7):403-413.

12. Abboudi $H$, Khan MS, Guru KA, et al. Learning curves for urological procedures: a systematic review. BJU Int. 2014;114(4):617-629.

13. Secin FP, Savage C, Abbou C, et al. The learning curve for laparoscopic radical prostatectomy: an international multicenter study. J Urol. 2010;184(6): 2291-2296.

14. Hruza M, Weiss HO, Pini G, et al. Complications in 2200 consecutive laparoscopic radical prostatectomies: standardised evaluation and analysis of learning curves. Eur Urol. 2010;58(5):733-741.

15. Jancke G, Rosell J, Jahnson S. Impact of surgical experience on recurrence and progression after transurethral resection of bladder tumour in non-muscleinvasive bladder cancer. Scand J Urol. 2014;48(3): 276-283.

16. Nguyen CT, Gao T, Hernandez AV, Jones JS. Can residents perform transrectal ultrasound-guided prostate biopsy with patient comfort comparable to biopsy performed by attending staff urologists? Prostate Cancer Prostatic Dis. 2010;13(1):52-57.

17. Reis LO, Sanches BC, de Mendonca GB, et al. Gleason underestimation is predicted by prostate biopsy core length. World J Urol. 2014 [Epub ahead of print].

18. Jagsi R, Kitch BT, Weinstein DF, Campbell EG, Hutter M, Weissman JS. Residents report on adverse events and their causes. Arch Intern Med. 2005;165 (22):2607-2613.

19. Zegers M, de Bruijne MC, Wagner C, et al. Adverse events and potentially preventable deaths in Dutch hospitals: results of a retrospective patient record review study. Qual Saf Health Care. 2009;18(4): 297-302.

20. van Vuuren W, Shea CE, van der Schaaf TW. The Development of an Incident Analysis Tool for the Medical Field. Eindhoven, The Netherlands: Eindhoven University of Technology; 1997.

21. van der Schaaf TW, Habraken MMP. PRISMAMedical: A Brief Description. Eindhoven, The Netherlands: Eindhoven University of Technology; 2005.

22. Viera AJ, Garrett JM. Understanding interobserver agreement: the kappa statistic. Fam Med. 2005;37(5): 360-363.

23. Ericsson KA. Deliberate practice and the acquisition and maintenance of expert performance in medicine and related domains. Acad Med. 2004;79(10 Suppl):S70-S81.

24. van Merrienboer JJG, Kirschner PA. Ten Steps to Complex Learning: A Systematic Approach to FourComponent Instructional Design. New York/London: Routledge; 2013. 78-111.

25. Ten Cate O. Nuts and bolts of entrustable professional activities. J Grad Med Educ. 2013;5(1):157-158.

26. Aggarwal R, Grantcharov T, Moorthy K, et al. Toward feasible, valid, and reliable video-based assessments of technical surgical skills in the operating room. Ann Surg. 2008;247(2):372-379.

27. Zevin B, Bonrath EM, Aggarwal R, et al. Development, feasibility, validity, and reliability of a scale for objective assessment of operative performance in laparoscopic gastric bypass surgery. J Am Coll Surg. 2013;216(5):955-965 [e8; quiz 1029-1031, 1033].

28. Haynes $A B$, Weiser $T G$, Berry $W R$, et al. A surgical safety checklist to reduce morbidity and mortality in a global population. N Engl J Med. 2009;360(5):491-499.

29. Ahmed K, Khan N, Khan MS, Dasgupta P. Development and content validation of a surgical safety checklist for operating theatres that use robotic technology. BJU Int. 2013;111(7):1161-1174.

30. Ericsson KA. Deliberate practice and acquisition of expert performance: a general overview. Acad Emerg Med. 2008;15(11):988-994.

31. Blessing $S$, Anderson J. How people learn to skip steps. J Exp Psychol Learn Mem Cognit. 1996;22(3):576-598.

32. Howell W. The Empathic Communicator. Bellmont, CA: Wadsworth; 1982.

33. Crandall SJ, George G, Marion GS, Davis S. Applying theory to the design of cultural competency training for medical students: a case study. Acad Med. 2003;78 (6):588-594. 